\title{
Experimental Design and Validation of an Accelerated Random Vibration Fatigue Testing Methodology
}

\author{
Yu Jiang, ${ }^{1}$ Gun Jin Yun, ${ }^{2}$ Li Zhao, ${ }^{2}$ and Junyong Tao ${ }^{1}$ \\ ${ }^{1}$ Science and Technology on Integrated Logistics Support Laboratory, College of Mechatronic Engineering and Automation, \\ National University of Defense Technology, Changsha, Hunan 410073, China \\ ${ }^{2}$ Department of Civil Engineering, The University of Akron, Akron, OH 44321, USA
}

Correspondence should be addressed to Yu Jiang; jiangyu@nudt.edu.cn

Received 13 May 2015; Revised 17 July 2015; Accepted 22 July 2015

Academic Editor: Gilbert-Rainer Gillich

Copyright (C) $2015 \mathrm{Yu}$ Jiang et al. This is an open access article distributed under the Creative Commons Attribution License, which permits unrestricted use, distribution, and reproduction in any medium, provided the original work is properly cited.

\begin{abstract}
Novel accelerated random vibration fatigue test methodology and strategy are proposed, which can generate a design of the experimental test plan significantly reducing the test time and the sample size. Based on theoretical analysis and fatigue damage model, several groups of random vibration fatigue tests were designed and conducted with the aim of investigating effects of both Gaussian and non-Gaussian random excitation on the vibration fatigue. First, stress responses at a weak point of a notched specimen structure were measured under different base random excitations. According to the measured stress responses, the structural fatigue lives corresponding to the different vibrational excitations were predicted by using the WAFO simulation technique. Second, a couple of destructive vibration fatigue tests were carried out to validate the accuracy of the WAFO fatigue life prediction method. After applying the proposed experimental and numerical simulation methods, various factors that affect the vibration fatigue life of structures were systematically studied, including root mean squares of acceleration, power spectral density, power spectral bandwidth, and kurtosis. The feasibility of WAFO for non-Gaussian vibration fatigue life prediction and the use of non-Gaussian vibration excitation for accelerated fatigue testing were experimentally verified.
\end{abstract}

\section{Introduction}

Many engineering structures usually undergo vibration loading. Fatigue is the most commonly encountered type of failure for structures operating under dynamic loading. Vibration fatigue is more complicated than general cyclic fatigue. To ensure the reliability and safety of structures during the operation, we need timely validation of long-term durability of engineering structures under their service vibration environment. This is usually done by the laboratory vibration tests. However, operational life under normal vibration conditions could be too long that the laboratory vibration tests at those levels would not be possible for many structures and materials. Accelerated testing provides time and cost saving compared with testing at normal conditions. Therefore it is necessary to perform accelerated vibration testing in a laboratory environment, which in terms of loading is considerably more severe than the operative one. Then the operative life duration is estimated by relating the structural fatigue life tested in the laboratory condition by a proper scaling factor.

In recent years, experimental methods for accelerated vibration fatigue testing are continuously under development. The work by Allegri and Zhang [1] addressed the usage of inverse power laws in accelerated fatigue testing under wide-band Gaussian random loading. The aim was not at predicting an absolute value of fatigue life but assessing the relative accumulation of fatigue damage. Özsoy et al. [2] proposed an accelerated life testing approach for aerospace structural components. A closed-loop system driven by power spectral density profiles was employed to run the constant amplitude resonance test. By changing the test durations and accordingly the mission profile amplitudes, a simple equation was proposed which relates accelerated test durations with the equivalent alternating stresses. Shires [3] discussed the time compression (test acceleration) of broadband random vibration tests. Conventionally, the test level is accelerated from the root mean acceleration and an 
assumed power constant $(k=2)$ is applied. The MinerPalmgren hypothesis of accumulated fatigue is used to reassess the potential error in test severity, which shows a substantially reduced sensitivity to the value of $k$ depending on the distribution of actual vibration intensities around the time-compressed test intensity. Xu et al. [4] developed a method for extracting the information on the frequency of the events expected in the service life from a time series based on wavelet analysis, clustering, and Fourier analysis. The identified events and their corresponding data are used to generate the accelerated durability testing PSD profiles, which can be directly applied as the driven profile in the lab test. Yun et al. [5] developed a vibration-based closedloop high-cycle resonant fatigue testing system. To minimize the testing duration, the test setup was designed for a baseexcited multiple-specimen arrangement driven in a highfrequency resonant mode, which allows completion of fatigue testing in an accelerated period. Česnik et al. [6] proposed an improved accelerated fatigue testing methodology based on the dynamic response of the test specimen to the harmonic excitation in the near-resonant area with simultaneous monitoring of the modal parameters. The measurements of the phase angle and the stress amplitude in the fatigue zone were used for the real-time adjustment of the excitation signal according to the changes in the specimen's modal parameters. Pothula et al. [7] addressed applicability of various theories for estimation of failure time in normal usage and accelerated condition for Gaussian random vibration testing. Another issue addressed was whether application of damping material makes any difference. Experimentally observed failure time in random vibration for both bare and damped beams under random vibration was compared, and the exponent in terms of both $\mathrm{g}^{2} / \mathrm{Hz}$ and $G_{\mathrm{rms}}$ for accelerated testing was obtained for bare and damped beams. Vibration fatigue analysis of a cantilever beam under white noise random input using several vibration fatigue theories was performed by Eldogan and Cigeroglu [8]. Fatigue life calculations by utilizing time domain (rainflow counting method) and frequency domain methods were repeated for different damping ratios and the effect of damping ratio was studied. Fatigue tests were performed on cantilever beam specimens and fatigue life results obtained experimentally were compared with that of in-house numerical codes. It was observed that the fatigue life result obtained from Dirlik method is considerably similar to that of the rainflow counting method.

The vibration loading in the above studies is limited to sinusoidal loading with constant amplitude or Gaussian random loading with alternating amplitude, and the random loading fatigue damage calculation is based on the assumption of Gaussian distribution. However, the dynamic loading shows non-Gaussianity in some practical applications, such as the ground vibration generated by wheeled vehicles travelling over irregular terrain, atmospheric turbulence for the aerospace sector, or wind pressure fluctuations on building envelopes [9]. Because traditional Gaussian random vibration test signals cannot accurately represent the nonGaussian vibration signal with high-peak characteristics seen in the real-life use of many structures, the latest MIL-STD$810 \mathrm{G}$ standard also requires test engineers to "ensure that test and analysis hardware and software are appropriate when non-Gaussian distributions are encountered" (refer to Method 525 on Page 514.6A-5 in literature [10]). For this purpose, the non-Gaussian vibration controller has just been developed by few manufacturers (such as Econ Corporation and Vibration Research Corporation) in recent years. Since the basic purpose of the non-Gaussian vibration controller is to simulate the real non-Gaussian vibration environment of some products, it is meaningful to carry out further experimental research on how to use non-Gaussian vibration in accelerated fatigue testing.

Generally, conservative or incorrect results will be obtained if non-Gaussianity is ignored during fatigue damage estimation and fatigue life prediction. Although in recent years there have been few studies on the non-Gaussian random vibration fatigue theory, the studies described in literature [11-14] are directly based on non-Gaussian response without considering non-Gaussian excitation and structural dynamics characteristic. However, in the laboratory vibration test, the main consideration is the vibration excitation profile. Therefore, there is a "gap" between theoretical research and engineering applications and it is necessary to establish a link between the Gaussian or non-Gaussian vibration excitation and structural vibration fatigue life, which will facilitate the design and statistical analysis of the accelerated vibration test.

Fatigue damage as a result of random loading can be assessed in either the time or frequency domain. In the time domain, the rainflow counting method is universally accepted for random vibration fatigue analysis. WAFO (Wave Analysis for Fatigue and Oceanography) is a toolbox of MATLAB routines for statistical analysis and simulation of random waves and random loads [15]. The main purpose of WAFO is for scientific research, and thus the aim of WAFO is not to contain all the features of the commercial software. Nevertheless, it is also widely used in industry. So far, there has been no report on WAFO applied to non-Gaussian vibration fatigue analysis. Therefore, this paper is not about proposing another method for predicting fatigue life. Rather, the objectives of this study are as follows: (1) develop a hybrid test strategy for the accelerated random vibration fatigue test, which can generate a design of the experimental test plan, significantly reduce test times and costs, and avoid complex finite element modeling and verification process and the risk of inaccuracies caused by modeling; (2) verify the feasibility of WAFO for non-Gaussian vibration fatigue life prediction; (3) experimentally and numerically investigate all the factors affecting the structure random vibration fatigue life; (4) explore the possibility of non-Gaussian vibration for accelerated fatigue testing.

\section{Theoretical Analysis and Damage Model}

2.1. Damage Model for Gaussian Random Vibration Excitation. Firstly the analysis starts from the most basic description of the material fatigue in terms of $S-N$ curve. Typically ideal mathematical expression for $S-N$ curve is written as follows:

$$
N=c S^{-b}
$$


where $S$ denotes the stress amplitude, $N$ denotes the stress cycles resulting in the failure, and $b$ and $c$ are the constant fatigue parameters that depend on the material.

On the base of the famous Miner cumulative fatigue damage criterion, the fatigue damage under a joint action of different amplitudes of stress is

$$
D=\sum_{i} \frac{n_{i}}{N_{i}}
$$

where $n_{i}$ is the number of cycles applied at fixed stress amplitude $S_{i}, N_{i}$ is the number of cycles the material can withstand at applied fixed stress amplitude $S_{i}$, and $D$ is cumulative fatigue damage (fatigue failure generally considered to occur at $D=1$ ).

Substituting (1) into (2), the following is obtained:

$$
D=\sum_{i} \frac{n_{i}}{c S_{i}^{-b}}=\sum_{i} \frac{n_{i}}{c} S_{i}^{b} .
$$

For continuous time histories of random stress, (3) can be written in the form of the following integral [16]:

$$
D=v_{0}^{+} T \int_{0}^{\infty}\left[\frac{p(S)}{\left(c S^{-b}\right)}\right] d S=\frac{v_{0}^{+} T}{c} \int_{0}^{\infty} p(S) S^{b} d S,
$$

where $T$ is the total time of exposure to the random vibration excitation, $p(S)$ denotes the probability density function of random stress response on the specimen, $v_{0}^{+}$is the average number of the zero upcrossings per unit time in the stress time history.

The specimen under the vibration test generally can be approximated as a linear system and the excitation generated by the vibration test equipment can be regarded as the input of the system. As the frequency response characteristics of the specimen are similar to a narrow-band filter, it can be considered that, under stationary Gaussian random excitation (either broad-band or narrow-band), the stress response of the specimen is close to the stationary narrow-band Gaussian distribution. When the random stress response approximates a stationary narrow-band Gaussian distribution, according to the random-process theory, the amplitude probability density function of the stress $p(S)$ has the following Rayleigh form [16]:

$$
p(S)=\frac{S}{\sigma_{s}^{2}} e^{-S^{2} / 2 \sigma_{S}^{2}},
$$

where $\sigma_{S}$ is the RMS value of the stress (i.e., standard deviation). Substituting (5) into (4) and doing the integration, the following equation could be obtained:

$$
D=\frac{v_{0}^{+} T}{c}\left[\sqrt{2} \sigma_{S}\right]^{b} \Gamma\left[1+\frac{b}{2}\right] .
$$

Herein $\Gamma$ represents the Gamma function.

Engineering practice shows that the damping ratio $\xi$ of a general structure is usually much less than 1 , for example, a small value of 0.05 or less. According to the literature [17], on the assumption of a linear system with small damping, the approximate calculation formula for $\sigma_{S}$ is

$$
\sigma_{S} \approx k \sqrt{\frac{G_{a}\left(f_{1}\right)}{\pi f_{1} \xi}},
$$

where $f_{1}$ is the first-order natural frequency of the specimen, $\xi$ denotes the equivalent damping ratio (generally assumed as $\xi \leq 0.1), k$ represents proportional constant related to the specimen, and $G_{a}\left(f_{1}\right)$ is the magnitude of the acceleration PSD of the input vibration excitation at the natural frequency $f_{1}$ of the specimen.

Under the assumption of small damping, $v_{0}^{+} \approx f_{1}$. Then substitute (7) into (6) to obtain

$$
\begin{aligned}
D & \approx \frac{f_{1} T k^{b}}{c}\left[\frac{2 G_{a}\left(f_{1}\right)}{\pi f_{1} \xi}\right]^{b / 2} \Gamma\left[1+\frac{b}{2}\right] \\
& =k_{1} T\left[\frac{G_{a}\left(f_{1}\right)}{\xi}\right]^{b / 2} f_{1}^{(1-b / 2)},
\end{aligned}
$$

where $k_{1}=\left(k^{b} / c\right)[2 / \pi]^{b / 2} \Gamma[1+b / 2]$. For the deterministic specimen material, $k_{1}$ is a proportional constant.

The fatigue failure is generally regarded to occur when $D=1$. The structural vibration fatigue life $T_{G}$ subject to Gaussian random vibration excitation can be obtained according to (8):

$$
T_{G}=\frac{f_{1}^{(b / 2-1)}}{k_{1}}\left[\frac{\xi}{G_{a}\left(f_{1}\right)}\right]^{b / 2} .
$$

Considering the commonly used engineering material, typically $b$ has a value range of $4-25$. From (9) it can be seen that, on the Gaussian random vibration excitation, when the structure dynamics parameters such as $f_{1}$ and $\xi$ are fixed, the structural vibration fatigue life $T_{G}$ is inversely proportional to the magnitude $G_{a}\left(f_{1}\right)$ of the PSD of the Gaussian random vibration excitation at the first natural frequency of the structure. As the increase (or decrease) of $G_{a}\left(f_{1}\right), T$ will undergo an exponential decay (or growth).

According to (9), the structural vibration fatigue lives under two different Gaussian random acceleration excitations are achieved, respectively, as

$$
\begin{aligned}
& T_{G 1}=\frac{f_{1}^{(b / 2-1)}}{k_{1}}\left[\frac{\xi}{G_{a 1}\left(f_{1}\right)}\right]^{b / 2}, \\
& T_{G 2}=\frac{f_{1}^{(b / 2-1)}}{k_{1}}\left[\frac{\xi}{G_{a 2}\left(f_{1}\right)}\right]^{b / 2} .
\end{aligned}
$$

According to (10) and (11), the following can be obtained:

$$
\frac{T_{G 1}}{T_{G 2}}=\left[\frac{G_{a 2}\left(f_{1}\right)}{G_{a 1}\left(f_{1}\right)}\right]^{b / 2} .
$$

Obviously, (12) above is the inverse power-law model in the literatures, which is often used to describe the accelerated 


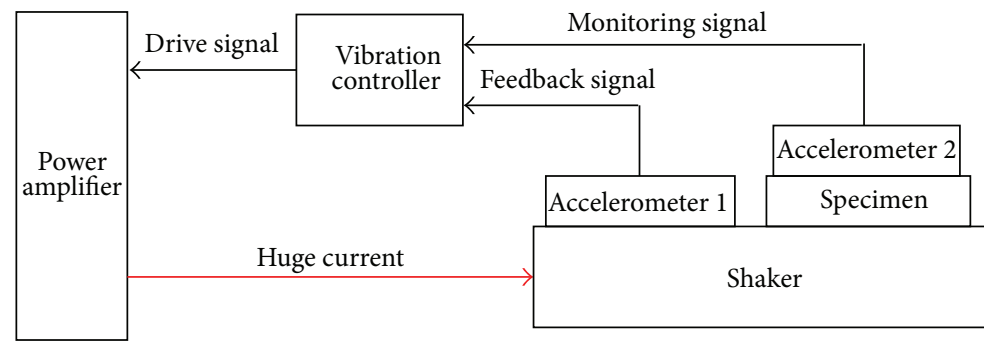

FIGURE 1: Closed-loop vibration fatigue test system configuration.

vibration test. From the derivation above, as long as the structural FRF of a system is similar to a narrow-band filter (actually this condition is applicable in most engineering structures) and the structural random response is subject to a Gaussian distribution, then it is able to use (12) to model the vibration acceleration test. Thus, (12) applies only to describe the accelerated Gaussian random vibration fatigue test.

2.2. Damage Model for Non-Gaussian Random Vibration Excitation. The following will continue to discuss the damage model for non-Gaussian random vibration excitation. When the random stress response approximates a stationary narrowband non-Gaussian distribution, it is possible to add nonGaussian correction factor $\lambda$ based on (8) to describe the impact of the kurtosis value of the stress response on the cumulative vibration fatigue damage:

$$
D=\lambda k_{1} T\left[\frac{G_{a}\left(f_{1}\right)}{\xi}\right]^{b / 2} f_{1}^{(1-b / 2)}
$$

It is obvious that the non-Gaussian correction factor $\lambda$ is proportional to the kurtosis value of stress response. Furthermore, the kurtosis value of stress response depends on the kurtosis value of vibration excitation and the kurtosis transfer function of the structure. However, according to the existing random vibration theory, it is difficult to obtain the kurtosis transfer function similar to frequency response function by theoretical analysis. Therefore, this paper will study the influence factors for the kurtosis value of the stress response or the non-Gaussian correction factor $\lambda$ by experimental method, which will be described in detail in Section 4.1.

\section{Accelerated Random Vibration Fatigue Test System}

3.1. Design of Random Vibration Fatigue Test System. The vibration fatigue test system consists of vibration table, power amplifiers, vibration controller, and accelerometers. As shown in Figure 1, the vibration controller used is a VT-9008 vibration controller from Econ Corporation, which contains up to 12 control modules. In addition to the traditional sine, Gaussian random, and shock tests, it is capable of generating a non-Gaussian random vibration signal with the specified power spectrum density and kurtosis and can be
TABLE 1: Material properties for Al 6061-T6 aluminum.

\begin{tabular}{lccc}
\hline Mass density & Young's modulus & Poisson's ratio & Yield strength \\
\hline $2,700 \mathrm{~kg} / \mathrm{m}^{3}$ & $68.9 \mathrm{GPa}$ & 0.33 & $276 \mathrm{MPa}$ \\
\hline
\end{tabular}

used to study the non-Gaussian random vibration fatigue. The vibration table (Brüel \& Kjær's V406 series) is able to output a maximum acceleration of $100 \mathrm{~g}$ and a frequency range of $5-9000 \mathrm{~Hz}$. The model of the two accelerometers is Dytran's 3030B4 with one providing the feedback signal to the controller and the other monitoring the vibration response of the specimen. The sensitivities of these two accelerometers were $9.86 \mathrm{mv} / \mathrm{g}$ and $9.71 \mathrm{mv} / \mathrm{g}$, respectively.

3.2. Design of Test Specimen and Fixture. In order to complete the vibration fatigue test within an appropriate time, the following notched specimen and supporting fixture were designed as shown in Figures 2 and 3. Four holes at one end of the specimen are used for mounting it on the shake table. On the other end, it was also designed with two holes: one for the installation of additional mass to accelerate the process of vibration fatigue failure and another hole for the installation of accelerometer to acquire the vibration response of the specimen. The material of specimen is Al 6061-T6 aluminum, due to its excellent mechanical properties and wide application in aerospace, machinery parts, structural engineering, modern architecture and transportation, and so forth. Material properties of Al 6061-T6 aluminum are shown in Table 1.

In order to obtain dynamic stress response, Vishay MicroMeasurements \& SR-4 strain gauges were used to measure the strain signal at the dangerous point, that is, the notch in the specimen. Strain gauges have a resistance value of $350 \pm 0.6 \%$ (Ohms) and a gauge factor of $2.125 \pm 0.5 \%$. Strain gauges in the form of quarter-bridge were mounted on the specimen as shown in Figure 4.

High-precision strain measurement system (Model 80008-SM) from Vishay Micro-Measurements Corporation is used for the acquisition, analysis, and processing of the strain signal. The strain apparatus communicates with the measurement software StrainSmart on the host computer using the network interface and is able to acquire and analyze 8-channel strain signals simultaneously. The sampling frequency of each channel has 5 options of $1000 / 500 / 200 / 100 / 10 \mathrm{~Hz}$ and up to $1 \mathrm{kHz}$. The strain measurement system has a self-calibration 


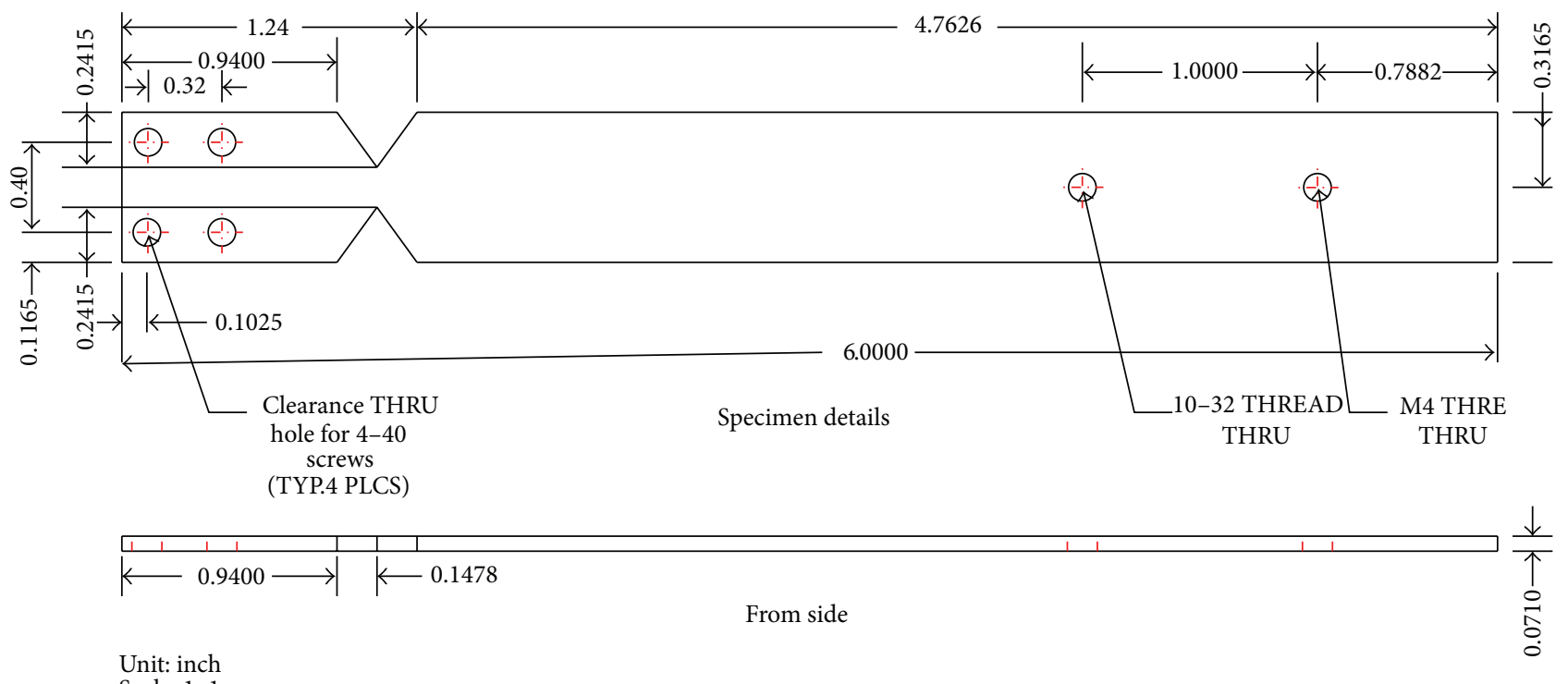

Scale: $1: 1$

Figure 2: Specimen dimension.

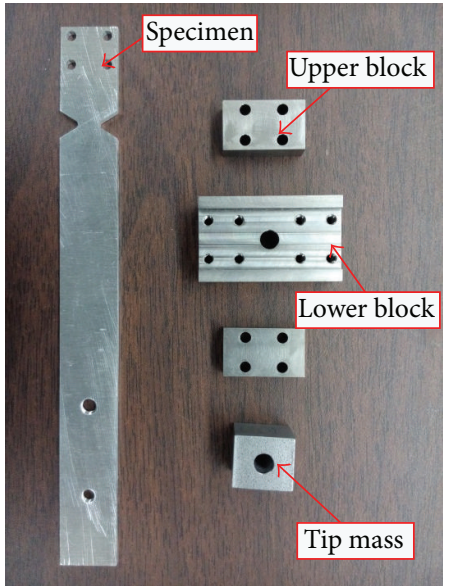

FiguRE 3: Fixture and specimen.



FIGURE 4: Specimen and strain gauge. function. The strain measurement ranges up to $\pm 310000 \mu \varepsilon$ and measurement resolution is up $0.5 \mu \varepsilon$.

\section{Experimental Design of Accelerated Random Vibration Fatigue Test Plan}

4.1. Design Considerations for Non-Gaussian Random Vibration Fatigue Test. One of the objectives in this paper is to investigate the influence factors associated with nonGaussian random vibrational excitation on the vibration fatigue life of a structure. Based on the random vibration theory, the systematic response depends on two factors, that is, the vibration excitation and the dynamic transfer characteristics of structure. Once the material, size, shape, and mounting are fixed, the dynamic characteristics are determined correspondingly. In order to ensure the credibility of the results of accelerated test, structural dynamics are normally kept same as service environment during the vibration test. Therefore, it is preferable to achieve accelerated results by changing some properties of the random vibration excitation. A complete description of the related parameters in the random vibrational excitation is necessary to be worked out before the experimental design.

The most common parameter used to describe the random vibration is power spectral density (PSD). However, PSD is not able to adequately portray all the characteristics of the random vibration. For example, with the same PSD and root mean square (RMS), the random signals can have completely different properties of the probability density distribution, as shown in Figure 5. Because the higher-order 


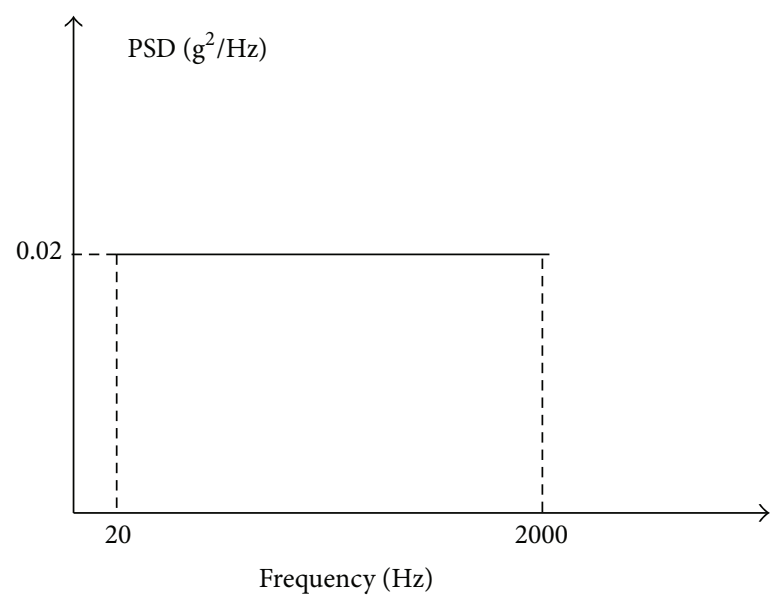

(a) Power spectral density

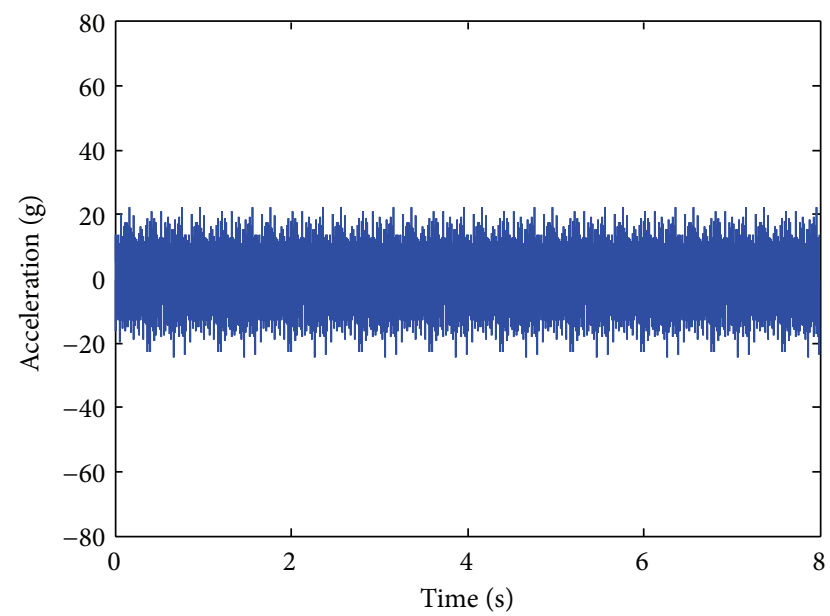

(c) Gaussian random vibration signal

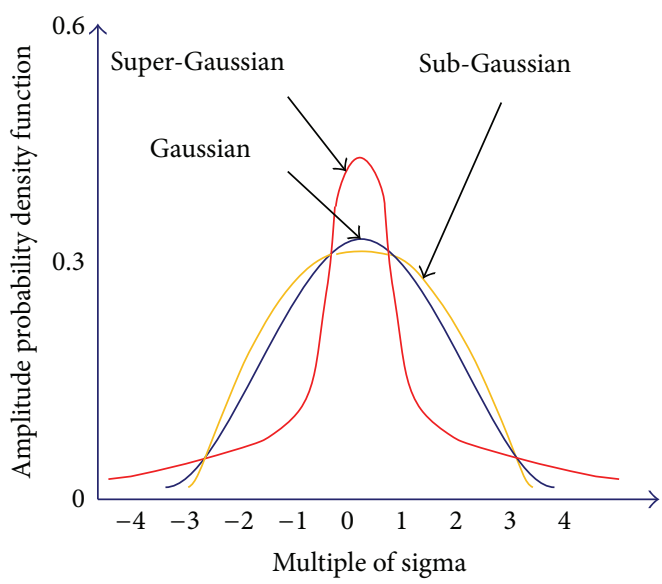

(b) Amplitude probability density function

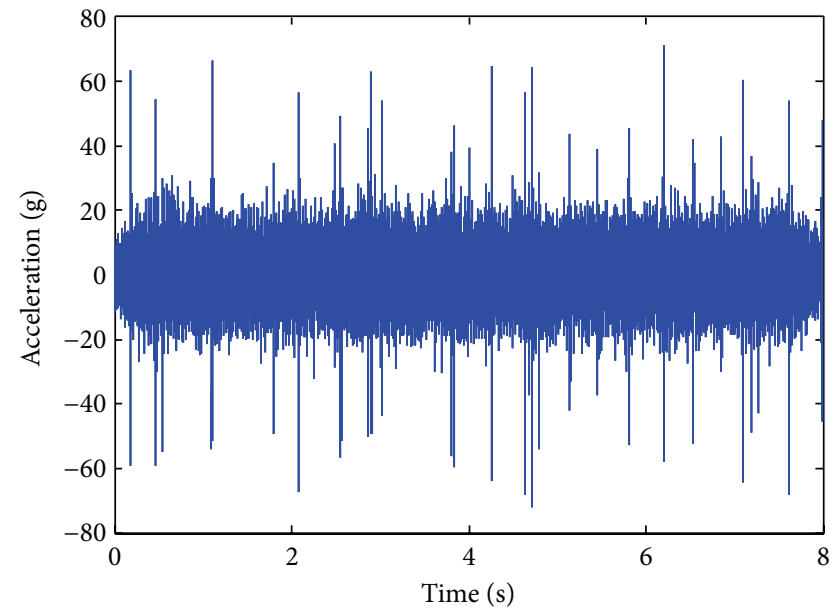

(d) Super-Gaussian random vibration signal

FIGURE 5: Gaussian and super-Gaussian vibration signals with the same PSD.

statistics over the second order are constantly zero for a Gaussian random process, only using the PSD function or selfcorrelation function can fully describe the characterization of the Gaussian random process. In addition to the PSD function, higher-order statistics (above the second order) also need to be supplied for a complete description of a nonGaussian random process. Skewness $S$ and kurtosis $K$ are the two parameters widely used in engineering to describe nonGaussian random process $X$, defined as follows:

$$
\begin{aligned}
S & =\frac{E[X-E(X)]^{3}}{\left\{E[X-E(X)]^{2}\right\}^{3 / 2}}, \\
K & =\frac{E[X-E(X)]^{4}}{\left\{E[X-E(X)]^{2}\right\}^{2}} .
\end{aligned}
$$

Skewness and kurtosis values of a Gaussian random process are 0 and 3 , respectively, while the kurtosis value for a non-Gaussian random process certainly is not equal to 3 and the skewness value may or may not be equal to 0 .
The skewness is used to describe the magnitude of a random process deviation from the symmetric probability density distribution. The nonzero skewness indicates the asymmetric distribution of the probability density. Kurtosis is a parameter describing the trailing probability density distribution of a random process, which not only can be used to distinguish between Gaussian and non-Gaussian random process, but also further classifies the non-Gaussian random process into sub-Gaussian and super-Gaussian random processes where sub-Gaussian random process $K<3$ and super-Gaussian random process $K>3$. The non-Gaussian vibration signals in engineering are usually super-Gaussian signals with highpeak characteristics.

In this paper, the five parameters used to fully describe a random vibration excitation are RMS, PSD, power spectral bandwidth, kurtosis, and skewness. Since most of the vibration signals in engineering and laboratory simulations are often symmetric, this paper focuses on investigating the influence of the first four parameters on the damage accumulation in vibration fatigue process. 
TABLE 2: Group A.

\begin{tabular}{lcccccc}
\hline Number of test profile & $\begin{array}{c}\text { Lower } \\
\text { frequency } \\
(\mathrm{Hz})\end{array}$ & $\begin{array}{c}\text { Upper } \\
\text { frequency } \\
(\mathrm{Hz})\end{array}$ & $\begin{array}{c}\text { Test profile parameters } \\
\text { PSD bandwidth } \\
(\mathrm{Hz})\end{array}$ & $\begin{array}{c}\text { Acceleration } \\
\text { PSD magnitude } \\
\left(\mathrm{g}^{2} / \mathrm{Hz}\right)\end{array}$ & $G_{\text {rms }}(\mathrm{g})$ & Kurtosis \\
\hline A1 & 15 & 215 & 200 & 0.031 & 2.50 \\
A2 & 15 & 115 & 100 & 0.031 & 3 \\
A3 & 15 & 65 & 50 & 0.031 & 3 \\
\hline
\end{tabular}

TABLE 3: Group B.

\begin{tabular}{|c|c|c|c|c|c|c|}
\hline \multirow[b]{2}{*}{ Number of test profile } & \multicolumn{6}{|c|}{ Test profile parameters } \\
\hline & $\begin{array}{c}\text { Lower } \\
\text { frequency } \\
(\mathrm{Hz})\end{array}$ & $\begin{array}{c}\text { Upper } \\
\text { frequency } \\
(\mathrm{Hz})\end{array}$ & $\begin{array}{l}\text { PSD bandwidth } \\
(\mathrm{Hz})\end{array}$ & $\begin{array}{c}\text { Acceleration } \\
\text { PSD magnitude } \\
\left(\mathrm{g}^{2} / \mathrm{Hz}\right)\end{array}$ & $G_{\mathrm{rms}}(\mathrm{g})$ & Kurtosis \\
\hline $\mathrm{B} 1$ & 15 & 65 & 50 & 0.031 & 1.25 & 3 \\
\hline B2 & 15 & 65 & 50 & 0.020 & 1.0 & 3 \\
\hline B3 & 15 & 65 & 50 & 0.010 & 0.7 & 3 \\
\hline
\end{tabular}

TABLE 4: Group C.

\begin{tabular}{lccccc}
\hline Number of test profile & $\begin{array}{c}\text { Lower } \\
\text { frequency } \\
(\mathrm{Hz})\end{array}$ & $\begin{array}{c}\text { Upper } \\
\text { frequency } \\
(\mathrm{Hz})\end{array}$ & $\begin{array}{c}\text { Test profile parameters } \\
\text { PSD bandwidth } \\
(\mathrm{Hz})\end{array}$ & $\begin{array}{c}\text { Acceleration } \\
\text { PSD magnitude } \\
\left(\mathrm{g}^{2} / \mathrm{Hz}\right)\end{array}$ & $\begin{array}{c}G_{\text {rms }}(\mathrm{g}) \\
\text { Kurtosis }\end{array}$ \\
\hline $\mathrm{C} 1$ & 15 & 65 & 50 & 0.02 & 1.0 \\
$\mathrm{C} 2$ & 15 & 65 & 50 & 0.02 & 1.0 \\
$\mathrm{C} 3$ & 15 & 65 & 50 & 0.02 & 1.0 \\
\hline
\end{tabular}

TABLE 5: Group D.

\begin{tabular}{|c|c|c|c|c|c|c|}
\hline \multirow[b]{2}{*}{ Number of test profile } & \multicolumn{6}{|c|}{ Test profile parameters } \\
\hline & $\begin{array}{c}\text { Lower } \\
\text { frequency } \\
(\mathrm{Hz})\end{array}$ & $\begin{array}{c}\text { Upper } \\
\text { frequency } \\
(\mathrm{Hz})\end{array}$ & $\begin{array}{c}\text { PSD bandwidth } \\
(\mathrm{Hz})\end{array}$ & $\begin{array}{l}\text { Acceleration } \\
\text { PSD magnitude } \\
\left(\mathrm{g}^{2} / \mathrm{Hz}\right)\end{array}$ & $G_{\mathrm{rms}}(\mathrm{g})$ & Kurtosis \\
\hline $\mathrm{D} 1$ & 15 & 115 & 100 & 0.02 & 1.4 & 5 \\
\hline D2 & 15 & 65 & 50 & 0.02 & 1.0 & 5 \\
\hline D3 & 15 & 35 & 20 & 0.02 & 0.63 & 5 \\
\hline
\end{tabular}

For this purpose, four groups of vibration fatigue tests were designed and listed in Tables 2-5.

In Table 2, Group A aims to investigate the influence of RMS and bandwidth of Gaussian random vibration excitation on the vibration fatigue.

In Table 3, Group B aims to investigate the influence of the PSD magnitude of Gaussian random vibration excitation at the structural first-order natural frequency on the vibration fatigue.

In Table 4, Group $\mathrm{C}$ is designed to investigate the influence of kurtosis value of a non-Gaussian random vibration excitation on the vibration fatigue.

In Table 5, Group D is designed to investigate the influence of the bandwidth of a non-Gaussian random vibration excitation on the vibration fatigue.
It can be seen that there is the same cross-sectional test parameter in every two adjacent groups such as A3 and B1, B2 and C1, and C2 and D2. The benefits of this sort of design are that the comparative analysis can be implemented by taking advantage of the test data in the previous group and it can also significantly reduce the total number of tests and sample size. In the following, a hybrid test method of actual test and numerical simulation will be presented that is used to derive test groups $\mathrm{A}, \mathrm{B}, \mathrm{C}$, and $\mathrm{D}$.

\subsection{Hybrid Test Strategy for Accelerated Random Vibration} Fatigue Test. According to the experimental design above, the test setup was eventually built as shown in Figure 6.

In order to save test time and ensure the validity of the test results, an idea of combining random vibration fatigue 

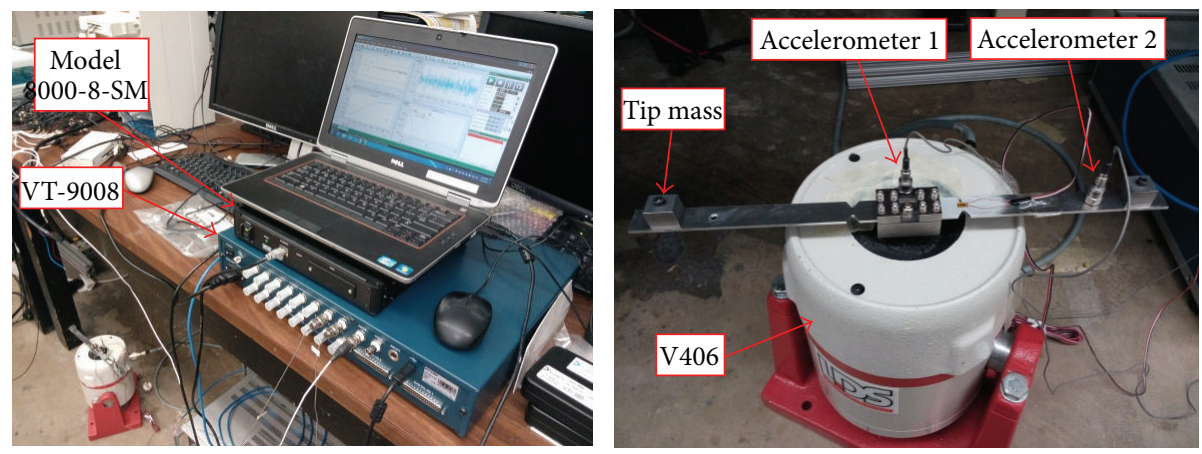

FiguRE 6: Experimental setup for accelerated random vibration fatigue test.

test and numerical simulation was proposed in this paper. Specifically the detailed idea and implementation process are introduced as follows.

Step 1 (determine the appropriate mass block by diagnostic tests). The first set of experiments were carried out by applying A1 from the experimental profile of Group A as the basic excitation condition of the shake table. Specimens were tested by adding three different mass blocks, that is, $15 \mathrm{~g}$, $20 \mathrm{~g}$, and $30 \mathrm{~g}$, at one end of the specimen aiming to obtain the corresponding time duration until fatigue fracture. It was found that only using the mass block of $20 \mathrm{~g}$ can obtain the best result. Also the length of the test time can be controlled in 1 to 2 hours, while $15 \mathrm{~g}$ mass block takes too long and $30 \mathrm{~g}$ mass block too short, and therefore ultimately $20 \mathrm{~g}$ mass was selected.

Step 2 (determine the natural frequency and damping ratio of the specimen through sine sweep test). Sine sweep test was implemented in a frequency range of 5-2000 Hz. Two accelerometers installed on the shake table and the specimen were used to acquire the vibration excitation and the response signals, respectively, for the calculation of the frequency response function. They were also used to determine the structural natural frequency of the specimen and damping ratio to ensure the frequency band of random vibration excitation covering the first-order natural frequency and fully exciting the resonant modes of the specimen to generate vibration fatigue. Figure 7 shows the frequency response function of the entire specimen structure.

It can be seen that there is only one specimen resonant frequency of $26.270 \mathrm{~Hz}$ within the frequency range of 5$2000 \mathrm{~Hz}$. According to the literature [5], when the vibration fatigue cracks occur to a structure, its natural frequency generally decreases slightly; however, the decline is not very significant and is generally only a few $\mathrm{Hz}$. Therefore, the four previously designed vibration excitation bands of 15$35 \mathrm{~Hz}, 15-65 \mathrm{~Hz}, 15-115 \mathrm{~Hz}$, and $15-215 \mathrm{~Hz}$ can guarantee covering its natural frequency in the whole testing process. Therefore it does not require to continuously track changes of the resonant frequency of the structure as the conventional sinusoidal vibration fatigue test and the random excitation is also much closer to the real vibrational service environment

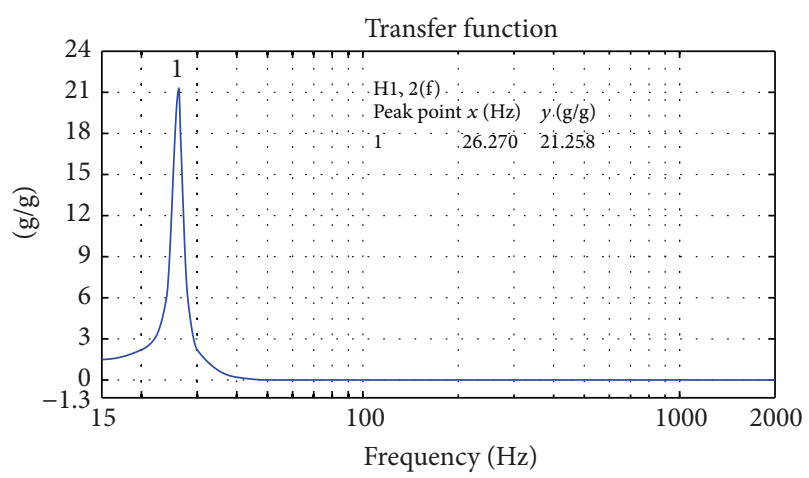

FIGURE 7: Frequency response function from sweep sine test.

of the specimen. Obviously it is an advantage of the random vibration fatigue testing. According to the measured frequency response function, the structural damping ratio was estimated as $2.52 \%$ using the half-power bandwidth method.

Step 3 (strain signal acquisition test (nondestructive vibration test)). From Section 2.1, the experimental program designed for the fatigue test, there are totally 9 different testing profiles if the two neighboring coincident experimental profiles are removed. Taking into account the dispersion characteristics of the fatigue life, in order to make the test results more credible, four specimens were tested for each test profile. In the meantime, the four test results were averaged to a final fatigue life. In this way, it requires $9 \times 4=36$ trials, which will be very time consuming. In order to tackle this problem, two strategies were used: The first one is if the fatigue failure times of the first three specimens are concentrated with a small dispersion, it is unnecessary to test the fourth specimen under the same fatigue test condition. The second one is the use of a combination of experimental tests and numerical simulations to actually reduce the number of destructive fatigue tests, that is, acquiring strain signals from the tests under nine different profiles at the stress concentration point under different random excitations by using strain apparatus and strain gauges and further obtaining the stress response signals according to the material properties; then, based on the stress response, using WAFO numerical analysis 


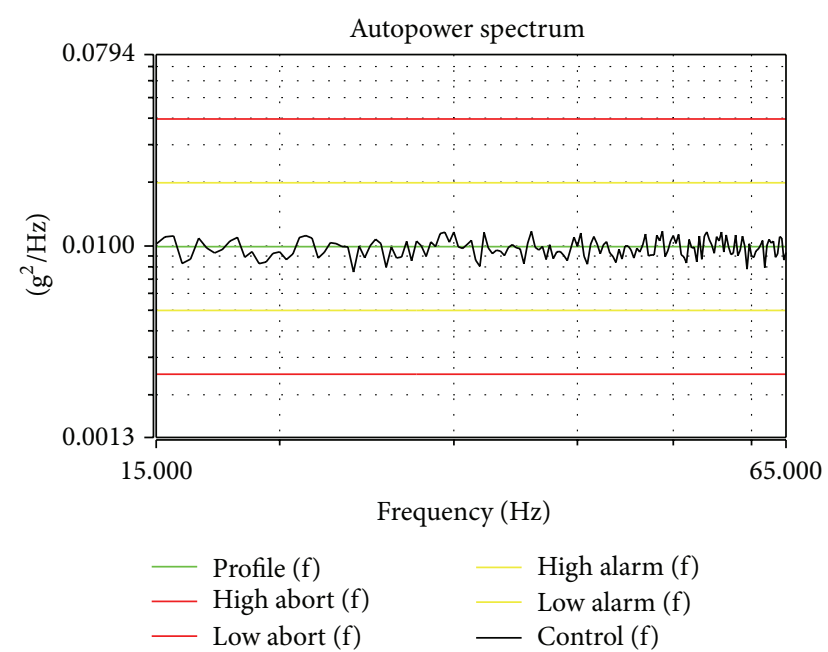

Figure 8: Test profile parameters (B3).

techniques to predict the structural fatigue life under different vibration test conditions which also provides a reference for the choice of test conditions to do the next vibration fatigue test; further selecting several test profiles having a predicted fatigue life within 3 hours to validate the effectiveness of the WAFO method under different random loadings. Once the effectiveness of WAFO method in predicting structural vibration fatigue life is fully validated, it is able to only carry out the vibration fatigue tests under a test profile with a predicted life within 3 hours while only strain signals acquired for the test profile have a predicted life of more than 3 hours. Therefore, the overall fatigue test time can be significantly reduced.

It should be noted that, in the acquisition process of test strain signals, a large measurement error can occur as the time accumulation of the vibration test and the likely damage of the specimen and the strain gauges. Thus once it is found that the measurement strain data becomes abnormal, the strain gauges and specimens are needed to be replaced timely. In this test, there were 5 strain gauges and 5 specimens used to ensure the accuracy of measurement strain data under different loading conditions. Figure 8 shows a schematic sectional view of test profile B3 and Figure 9 illustrates a time domain excitation signal according to B3. The acceleration response signal was measured by the monitoring accelerometer and shown in Figure 10. Figure 11 shows the strain response signal measured at the stress concentration point of the structure by the strain apparatus. Figure 12 shows the stress response signal obtained on the base of strain signals and material properties of the specimen.

After obtaining the stress response signal at the dangerous point, the material fatigue $S-N$ curves or related parameters of the structure are still required for the application of WAFO method in predicting the structural vibration fatigue life. In this paper, the fatigue properties of $\mathrm{Al}$ 6061-T6 aluminum alloy discussed in the literature [18] are adopted and show a good agreement with the actual test results.

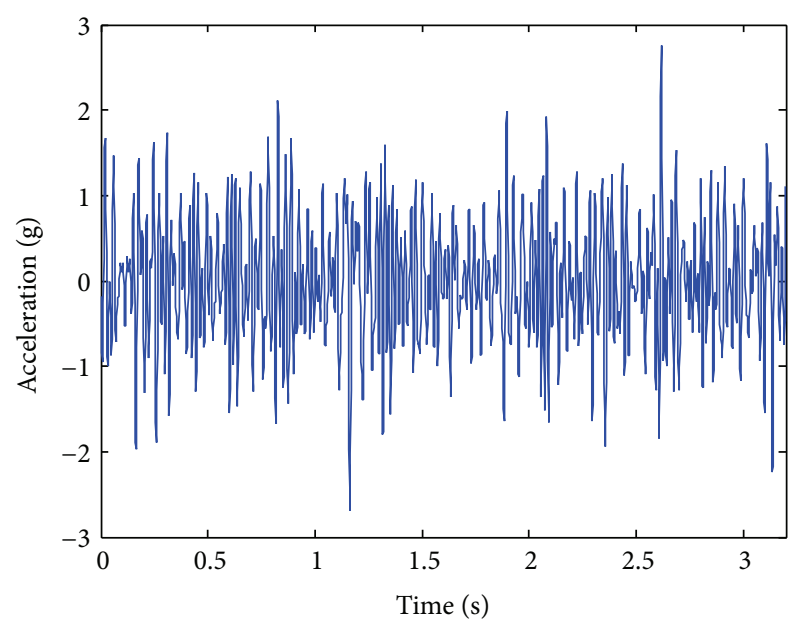

FIGURE 9: Vibration excitation signal under test profile B3.

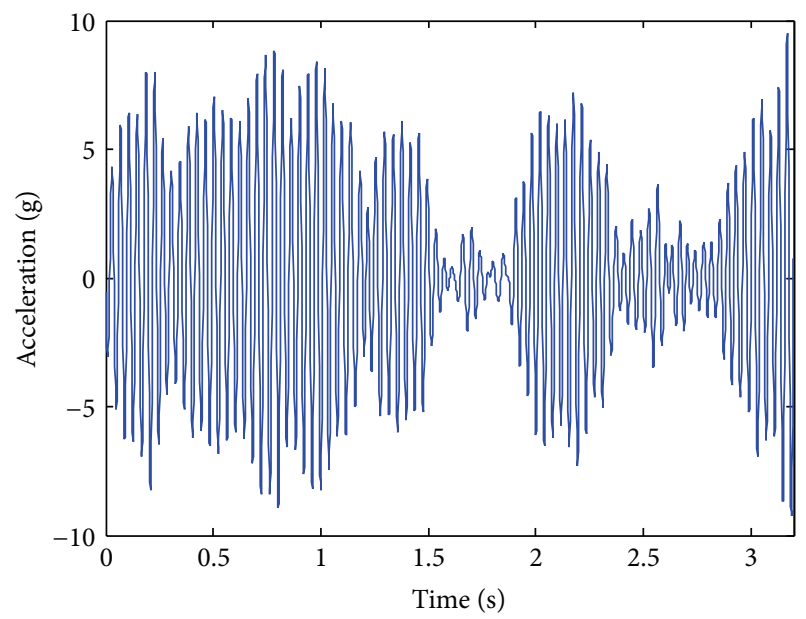

FIgURE 10: Vibration response signal under test profile B3.

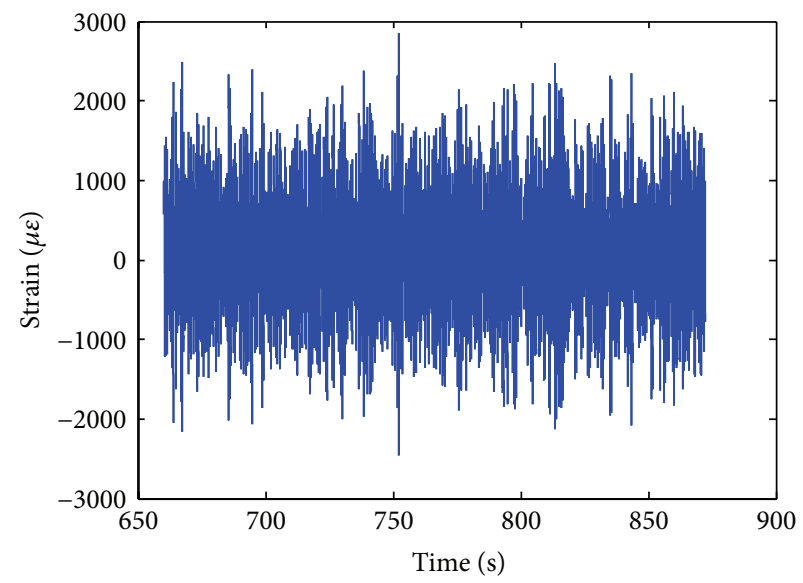

FIGURE 11: Strain signal under test profile B3. 




FIGURE 12: Stress signal under test profile B3.

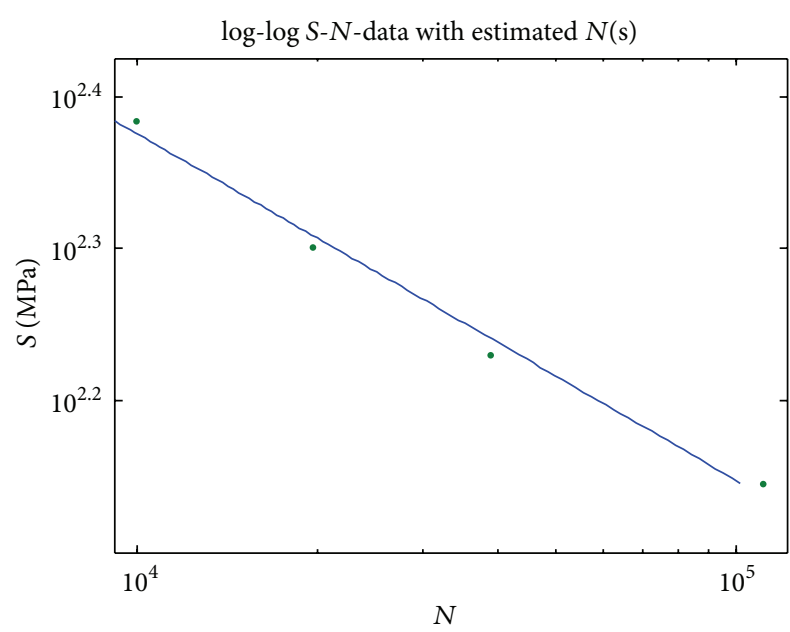

FIgURE 13: $S$-N curve for Al 6061-T6.

The double logarithmic fatigue $S$ - $N$ curve used in this study is illustrated in Figure 13. Figure 14 shows results from the rainflow fatigue counting method by applying WAFO to the stress response sequence shown in Figure 12. According to the rainflow counting results and material fatigue $S$ - $N$ curves, the corresponding fatigue life is easy to be predicted.

Step 4 (vibration fatigue failure test (destructive vibration fatigue test)). According to the stress response signals obtained from the acquired strain signals in the last step, WAFO numerical analysis techniques are employed to predict the fatigue life of the structure. It was found that only fatigue lives corresponding to test profiles B3 and D1 are relatively longer, that is, 14.86 and 3 hours, respectively, while in other tests the corresponding fatigue lives of the profiles are all less than 3 hours. Therefore, in order to fully validate accuracy of the WAFO method in the prediction of structural vibration fatigue life, the vibration fatigue failure test was carried out to the other 7 testing profiles except B3 and D1;



FIgURE 14: Rainflow cycle counts for stress signals in Figure 12.

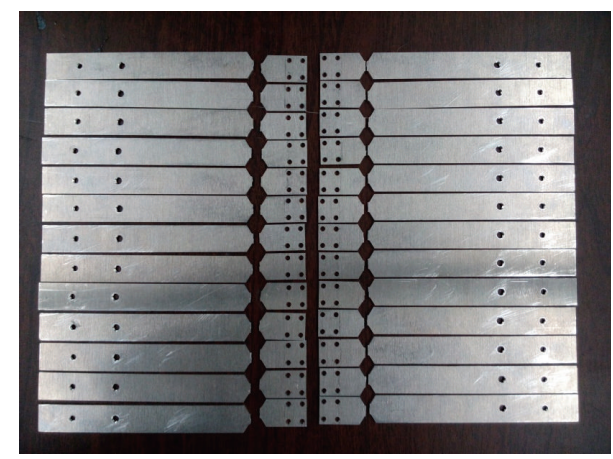

FIGURE 15: Fatigue specimens broken during this experiment.

in other words, the test continued until the specimens are completely fatigue-failed. Finally, 23 specimens were actually used to conduct the destructive fatigue test. If we consider the 3 broken specimens in the diagnostic test, a total of 26 specimens undertook fatigue fracture failure, as shown in Figure 15.

In the destructive fatigue test, in addition to the natural frequency drop with the fatigue crack initiation mentioned in other literature, another interesting phenomenon of natural frequency bifurcation was also observed, as shown in Figure 16. When the specimen has fatigue cracks, the first natural frequency declines slightly and then the curve of the transfer function changes from "single peak" into the neighboring "Twin Peaks." The amplitude of the transfer function at each peak is also smaller than the initial amplitude. Further, once the "Twin Peaks" phenomenon occurs, the complete fatigue fracture of the specimen will take place around 5 minutes later. Therefore, this phenomenon can be used as an 
TABLE 6: Test matrix and results.

\begin{tabular}{lccccc}
\hline Test group & Number of test profile & $n$ & $T$ (minute) & $T_{e}$ (minute) & $T_{p}$ (minute) \\
\hline \multirow{3}{*}{ A } & A1 & 4 & $64 ; 60 ; 62 ; 66$ & 63 & 68 \\
& A2 & 4 & $77 ; 64 ; 55 ; 58$ & 63.5 & 55 \\
\hline \multirow{3}{*}{ B } & A3 (B1) & 3 & $77 ; 52 ; 53$ & 61 & 69 \\
& B1 (A3) & 3 & $77 ; 52 ; 53$ & 61 & 69 \\
& B2 (C1) & 3 & $155 ; 133 ; 145$ & 144 & 156 \\
C & B3 & Strain acquisition test & & 892 \\
\hline & C1 (B2) & 3 & $155 ; 133 ; 145$ & 144 & 156 \\
& C2 (D2) & 3 & $102 ; 117 ; 110$ & 110 & 106 \\
D & D1 & 3 & $59 ; 73 ; 87$ & 73 & 90 \\
& D2 (C2) & 3 & Strain acquisition test & & 180 \\
& D3 & 3 & $102 ; 117 ; 110$ & 110 & 88 \\
\hline
\end{tabular}

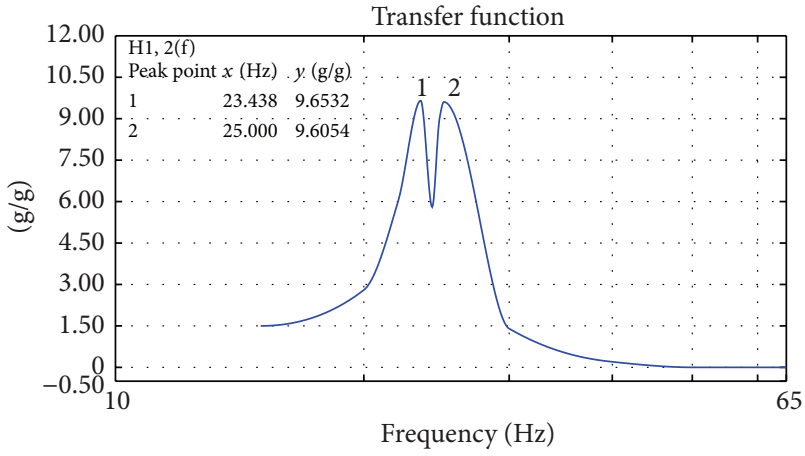

FIGURE 16: Bifurcation of natural frequency when fatigue cracks were developed.

effective means of real-time monitoring of the fatigue damage of the specimen in the vibration fatigue test process.

\section{Experimental Results and Discussions}

Detailed test results are shown in Table 6 , where $n$ is the number of tests conducted at a test profile level; $T$ is the real experimental time until fatigue broken failure; $T_{e}$ is its mean; $T_{p}$ is the predicted fatigue life by WAFO method based on the strain acquisition test results.

First, it is good to review the effectiveness of WAFO numerical analysis method. As can be seen from Table 6, the fatigue life $T_{e}$ obtained through the actual fatigue test was close to the fatigue life $T_{p}$ predicted by WAFO and they matched very well. It illustrates that WAFO fatigue life prediction method is applicable to both the Gaussian and non-Gaussian random vibration fatigue and can be used as an effective means of vibration fatigue simulation test. Next, the test results from each group are analyzed to reveal all possible impact factors for the structural vibration fatigue.

From the test results of Group A, though RMS values and bandwidths of $\mathrm{A} 1, \mathrm{~A} 2$, and $\mathrm{A} 3$ are different, there is no significant difference between the test result $T_{e}$ and the simulation result $T_{p}$ due to the same PSD magnitude designated at first-order natural frequency of the structure.

This shows that, considering the structural random vibration fatigue, as long as the first-order natural frequency of the structure is included in the excitation band and the PSD magnitude of a Gaussian random vibration excitation at the first-order natural frequency of the structure is kept consistent, the RMS value and excitation bandwidth of Gaussian random vibration have a limited impact on the vibration fatigue life. This is easy to understand and interpret as the magnitude of the structural random response depends on the energy distribution of the excitation at the resonance frequency of the structure.

The results of Group B further confirmed the above rules. Though B1, B2, and B3 have the consistent bandwidth, the vibration fatigue life of the structure has undergone a significant change by changing the PSD magnitude of Gaussian random vibration excitation at the first-order natural frequency of the structure to alter the excitation RMS.

The test results of Group C showed that the kurtosis value of non-Gaussian random vibration excitation also has a significant impact on the structural vibration fatigue life. With the same PSD and RMS, the higher the kurtosis value of non-Gaussian random vibration excitation is, the shorter the structural vibration fatigue life is. This supports the fact that the use of non-Gaussian vibration excitation for accelerated fatigue tests is possible.

Results from Group D showed that the bandwidth of nonGaussian random vibration excitation also has a significant impact on the structural vibration fatigue life. Under the condition of the same kurtosis value and the same PSD magnitude, the narrower the bandwidth of non-Gaussian random vibration excitation is, the shorter the structural vibration fatigue life is. This reveals that the use of nonGaussian vibration excitation for accelerated fatigue tests must consider the bandwidth factor.

In summary, a test strategy for the accelerated random vibration fatigue test is developed based on the hybrid 
method of actual test and numerical simulation. Detailed steps are introduced as follows:

(1) The characteristics of random vibration environment of engineering structures under actual service conditions should be measured and analyzed including both the PSD and kurtosis value in order to ensure whether a non-Gaussian distribution is applicable. The structural dynamics also need to be tested and analyzed including natural frequency, damping ratio, and other parameters.

(2) Based on the PSD of service vibration environment obtained in the last step, the corresponding Gaussian vibration environment is firstly reproduced on the shake table and the same or similar mounting of the structure is also applied for the purpose of ensuing that the structural dynamic parameters such as the natural frequency and damping ratio are consistent with the reality. According to the design idea of the test profile in Group B, the PSD is increased gradually while the stress response is measured at the critical points in the structure under different vibrational excitation until it is close to the material yield limit.

(3) If the actual vibration environment of the structure is subject to a non-Gaussian distribution, the corresponding non-Gaussian vibration environment is supposed to be reproduced on the shake table. In accordance with the design idea of the test profile in Group C, the kurtosis value of the random vibration excitation is increased gradually. Simultaneously the stress response is measured at the critical points in the structure under different vibrational excitation until it is close to the material yield limit.

(4) On the base of all the stress response measured in the second and third steps, WAFO numerical simulation analysis is used to predict the vibration fatigue life of the structure under different loading conditions. According to the predicted fatigue life, a few test profiles with shorter life are selected to carry out the actual vibration fatigue destructive tests. Also the results of destructive fatigue tests are used to validate and correct the results of WAFO method.

\section{Conclusions}

In this paper, a closed-loop system for the random vibration fatigue test was set up. The experimental procedure of the vibration fatigue test was carefully designed and combined with the WAFO fatigue simulation analysis. Finally a variety of influence factors on the structural vibration fatigue life were systematically studied in a significantly reduced time. The related main conclusions are listed as follows:

(1) For the Gaussian random vibration, the biggest factor affecting the structural vibration fatigue life is the PSD magnitude of a Gaussian random vibration excitation at the first-order natural frequency of the structure. On the other hand, the RMS value, bandwidth, and other factors of the
Gaussian random vibration excitation have a small effect on the structural vibration fatigue life.

(2) For the non-Gaussian random vibration, in addition to the PSD magnitude at the first-order natural frequency, both the bandwidth and kurtosis value of non-Gaussian random vibration excitation have a significant effect on the stress response of the structure and further significantly affect the structural vibration fatigue life.

(3) The WAFO-based fatigue life prediction method is applicable to both the Gaussian and non-Gaussian random vibration fatigue, in good agreement with the actual test results, and can be used as an effective means of vibration fatigue simulation test.

(4) A new test strategy for the accelerated Gaussian/nonGaussian random vibration fatigue test is developed based on the hybrid method of the actual test and numerical simulation, which avoids the complex finite element modeling and verification process (especially in the case of a complex structure) and the risk of inaccuracies in the model. Also it avoids the long testing time caused by the complete fatigue destructive test and reduces the sample size and, at the same time, ensures the accuracy and the effectiveness of the assessment results, which can be used to assess the long-term durability and fatigue reliability of engineering structures under random vibration environment.

\section{Conflict of Interests}

The authors declare that there is no conflict of interests regarding the publication of this paper.

\section{Acknowledgments}

The authors would like to proclaim sincere gratitude to all those who contributed to the success of the research project reported in this study. The authors gratefully acknowledge the financial support provided by National Natural Science Foundation of China (50905181). The authors appreciate the experimental support provided by $\mathrm{Ph} . \mathrm{D}$. candidate Ali Imani Azad (from Intelligent Structural Engineering and Health Monitoring Laboratory at The University of Akron). Without his help, the experimental work would not have been accomplished in time. The authors also would like to thank research technician Bill Wenzel (from College of Engineering, The University of Akron) for his strong support in manufacturing and machining of materials.

\section{References}

[1] G. Allegri and X. Zhang, "On the inverse power laws for accelerated random fatigue testing," International Journal of Fatigue, vol. 30, no. 6, pp. 967-977, 2008.

[2] S. Özsoy, M. Çelik, and F. S. Kadioglu, "An accelerated life test approach for aerospace structural components," Engineering Failure Analysis, vol. 15, no. 7, pp. 946-957, 2008.

[3] D. Shires, "On the time compression (test acceleration) of broadband random vibration tests," Packaging Technology and Science, vol. 24, no. 2, pp. 75-87, 2011. 
[4] K. Xu, Y. Wu, and Q. Wu, "Development of vibration loading profiles for accelerated durability tests of ground vehicles," in Proceedings of the Dynamic Systems and Control Conference and Bath/ASME Symposium on Fluid Power and Motion Control (DSCC '11), pp. 717-724, Arlington, Va, USA, November 2011.

[5] G. J. Yun, A. B. M. Abdullah, and W. Binienda, "Development of a closed-loop high-cycle resonant fatigue testing system," Experimental Mechanics, vol. 52, no. 3, pp. 275-288, 2012.

[6] M. Česnik, J. Slavić, and M. Boltežar, "Uninterrupted and accelerated vibrational fatigue testing with simultaneous monitoring of the natural frequency and damping," Journal of Sound and Vibration, vol. 331, no. 24, pp. 5370-5382, 2012.

[7] A. Pothula, A. Gupta, and G. R. Kathawate, "Fatigue failure in random vibration and accelerated testing," Journal of Vibration and Control, vol. 18, no. 8, pp. 1199-1206, 2012.

[8] Y. Eldogan and E. Cigeroglu, "Vibration fatigue analysis of a cantilever beam using different fatigue theories," in Topics in Modal Analysis, Volume 7: Proceedings of the 31st IMAC, A Conference on Structural Dynamics, 2013, Conference Proceedings of the Society for Experimental Mechanics Series, pp. 471-478, Springer, New York, NY, USA, 2014.

[9] Y. Jiang, J. Y. Tao, and D. Z. Wang, "Simulation of nonGaussian stochastic processes by amplitude modulation and phase reconstruction," Wind and Structures, vol. 18, no. 6, pp. 693-715, 2014.

[10] Department of Defense, MIL-STD-810G, Test Method Standard for Environmental Engineering Considerations and Laboratory Tests, Department of Defense, 2008.

[11] D. Benasciutti and R. Tovo, "Fatigue life assessment in nonGaussian random loadings," International Journal of Fatigue, vol. 28, no. 7, pp. 733-746, 2006.

[12] H. W. Cheng, J. Y. Tao, X. Chen, and Y. Jiang, "A method for estimating rainflow fatigue damage of narrowband nonGaussian random loadings," Proceedings of the Institution of Mechanical Engineers, Part C: Journal of Mechanical Engineering Science, vol. 228, no. 14, pp. 2459-2468, 2014.

[13] H. W. Cheng, J. Y. Tao, X. Chen, and Y. Jiang, "A spectral method to estimate fatigue life under broadband non-Gaussian random vibration loading," Journal of Vibroengineering, vol. 16, no. 2, pp. 596-607, 2014.

[14] H. Cheng, J. Tao, X. Chen, and Y. Jiang, "Fatigue reliability evaluation of structural components under random loadings," Proceedings of the Institution of Mechanical Engineers, Part O: Journal of Risk and Reliability, vol. 228, no. 5, pp. 469-477, 2014.

[15] P. A. Brodtkorb, P. Johannesson, G. Lindgren, I. Rychlik, J. Rydén, and E. Sjö, "WAFO-a Matlab toolbox for analysis of random waves and loads," in Proceeedings of the 10th International Offshore and Polar Engineering Conference, pp. 343-350, Seattle, Wash, USA, June 2000.

[16] S. H. Crandall and W. D. Mark, Random Vibration in Mechanical Systems, Academic Press, New York, NY, USA, 1963.

[17] H. Himelblau, D. L. Kern, J. E. Manning, A. G. Piersol, and A. Rubin, "Dynamic environmental criteria: NASA-HDBK-7005," in NASA Technical Handbook, NASA, Washington, DC, USA, 2001.

[18] G. T. Yahr, "Fatigue design curves for 6061-T6 aluminum," Journal of Pressure Vessel Technology, vol. 119, no. 2, pp. 211-215, 1997. 

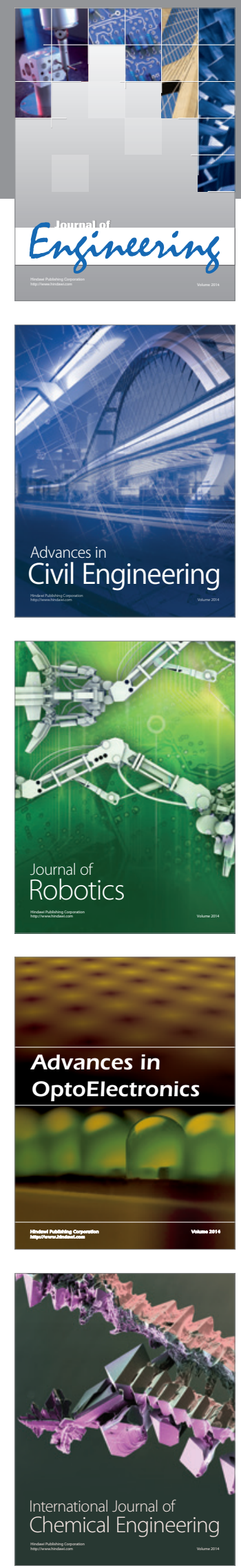



The Scientific World Journal
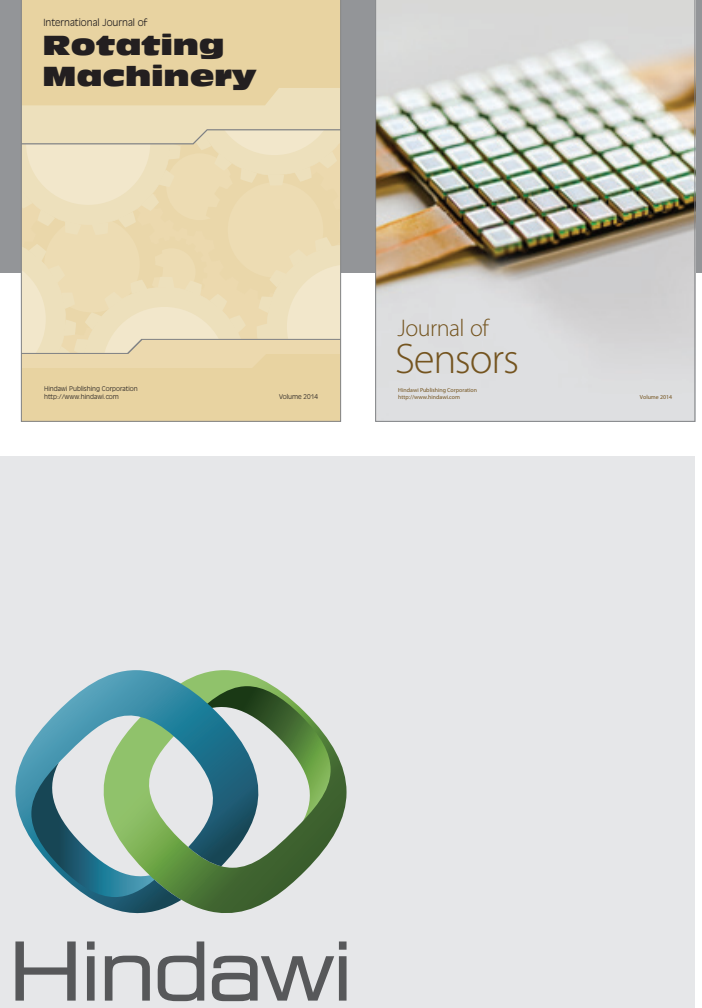

Submit your manuscripts at http://www.hindawi.com
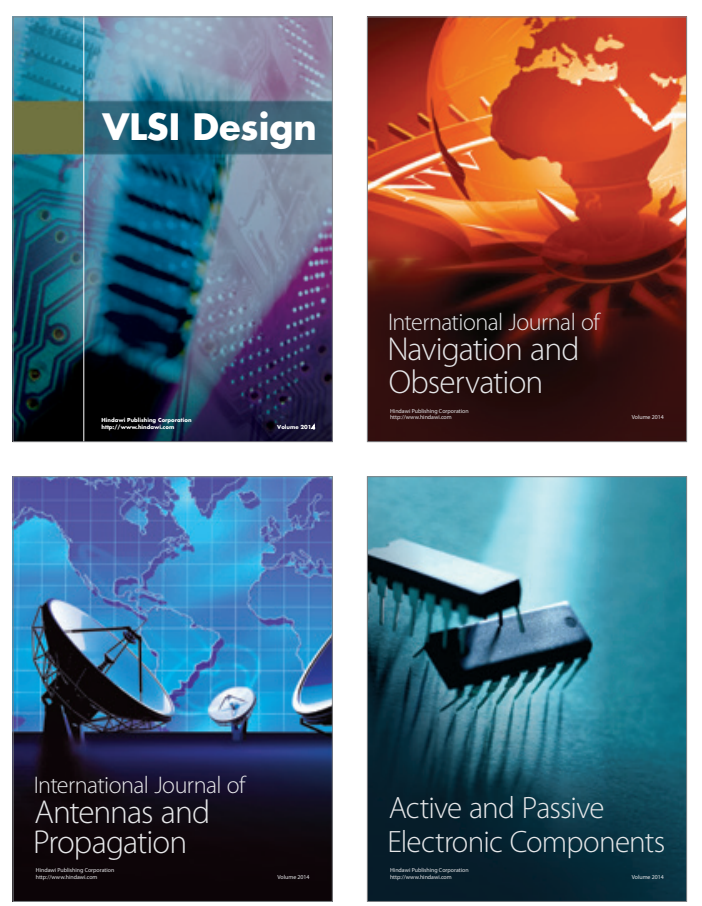
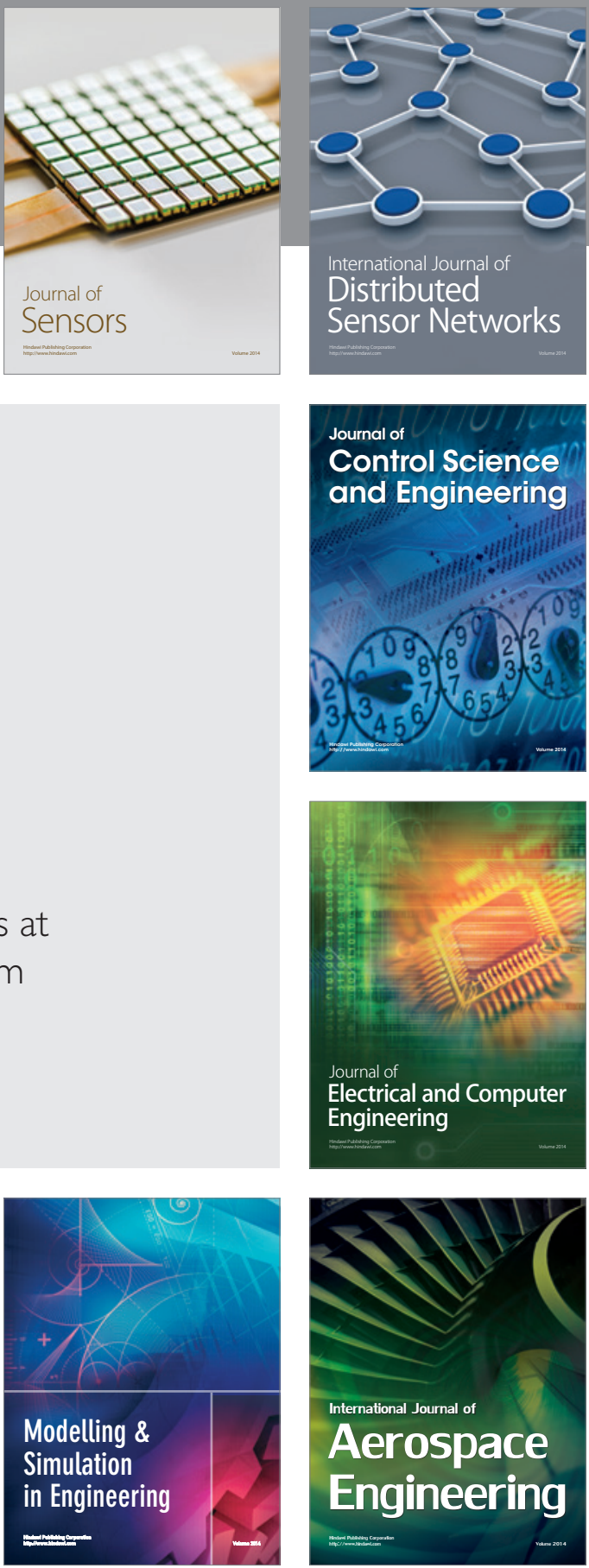

Journal of

Control Science

and Engineering
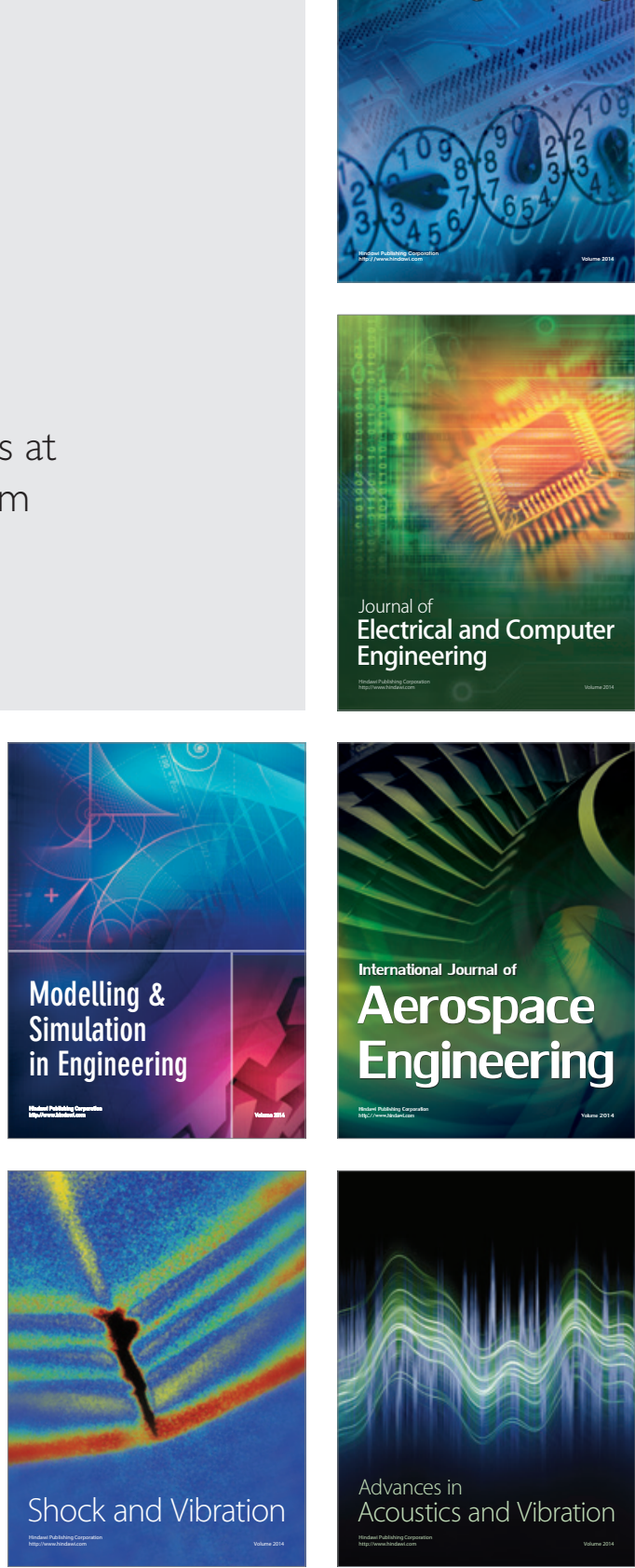